\title{
Immunohistochemical localization of collagen types I and VI in human skin wounds
}

\author{
P. Betz ${ }^{1}$, A. Nerlich ${ }^{2}$, J.Wilske ${ }^{1}$, J. Tübel ${ }^{1}$, R.Penning ${ }^{1}$, and W. Eisenmenger ${ }^{1}$ \\ Departments of Legal Medicine ${ }^{1}$ and Pathology ${ }^{2}$, University of Munich, Frauenlobstrasse 7a, D-80337 Munich, Germany
}

Received September 4, 1992 / Received in revised form January 24, 1993

\begin{abstract}
Summary. A total of 74 human skin wounds were investigated and collagen types I and VI were localized in the wound area by immunohistochemistry. Collagen type I appeared in the form of ramifying string-like structures after approximately 5-6 days, but positive reactions in the form of a spot-like staining around isolated fibroblasts also occurred in a skin wound aged 4 days. Collagen VI was detectable after a post-infliction interval of at least 3 days showing a strongly positive reacting network associated with fibroblasts in the wound area. Both collagens appeared almost constantly after a wound age of 6-7 days and could also be found in wounds aged a few months. Therefore, although a positive reaction for collagen type I in the form of string-like and ramifying structures around wound fibroblasts indicates a wound age of at least 5-6 days, a spot-like positive staining for collagen type I cannot exclude a wound age of at least 4 days. A positive staining for collagen type VI represents a postinfliction time of 3 days or more. The almost constant appearance of these collagen types suggests that negative results in a sufficient number of specimens indicate a wound age of less than 6-7 days, but cannot completely exclude longer post-infliction intervals. Since collagen type I and VI are also found in the granulation/scar tissue of lesions with advanced wound age, the immunohistochemical analysis of these proteins provides no further information for an age determination of older skin wounds.
\end{abstract}

Key words: Wound Age - Collagen Type I - Collagen Type VI - Immunhistochemistry

Zusammenfassung. In 74 menschlichen Hautwunden wurden Kollagen I und VI immunhistochemisch dargestellt. Kollagen I erschien in Form strangförmiger, mitunter sich bereits verzweigender und mit Fibroblasten assoziierter Strukturen im Wundgebiet frühestens nach einer Überlebenszeit von 5-6 Tagen, positiv reagierende fleckförmige Reaktionsprodukte um einzelne Fibroblasten fanden sich bereits in einer 4 Tage überlebten Wun-

Correspondence to: P. Betz de. Kollagen VI war frühestens ab einem Wundalter von 3 Tagen feststellbar und beide Kollagen-Typen konnten ab einem Wundalter von 6-7 Tagen nahezu regelmäßig im Untersuchungsgut nachgewiesen werden. Positiv reagierende strangförmige Strukturen für Kollagen I bzw. Kollagen VI belegen somit ein Mindestalter von 5-6 bzw. 3 Tagen, herdförmige, Fibroblasten-assoziierte Reaktionen für Kollagen I können im Wundgebiet bereits ab 4 Tagen Überlebenszeit auftreten. Wegen des nahezu regelmäßigen Nachweises der beiden Kollagen-Typen ab einem Wundalter von 6-7 Tagen kann bei Fehlen einer positiven Reaktion in einer ausreichenden Zahl von untersuchten Präparaten auf eine Überlebenszeit von weniger als 6-7 Tagen geschlossen werden; da negative Befunde jedoch immer mit Zurückhaltung interpretiert werden sollten, kann eine solche aber nicht mit letzter Sicherheit bewiesen werden. Da Kollagen I wie auch VI ebenfalls im Granulations- bzw. Narbengewebe länger überlebter Verletzungen wenn auch in abnehmender Intensität nachweisbar sind, können durch die immunhistochemische Darstellung dieser Proteine keine zusätzlichen Aussagen zur Überlebenszeit von Hautwunden mit fortgeschrittenem. Wundalter getroffen werden.

Schlüsselwörter: Wundalter - Kollagen Typ I - Kollagen Typ VI - Immunhistochemie

\section{Introduction}

Up to now 14 different collagen subtypes have been identified, 6 of which can be localized in human skin [18]. The use of the immunohistochemical detection of collagen types I, III and IV for a forensically applicable wound age-determination has previously been shown by Eisenmenger et al. [7], while studies dealing with the time-dependent appearance of collagen types III, IV, V and VII have been performed by Betz et al. $[3,4,5]$.

In the present study collagen type VI was localized to prove whether the analysis of this collagen type can provide further information for the age estimation of human 
skin wounds and the time-dependent appearance was compared with that of collagen type I, which represents another important interstitial collagen subtype.

\section{Material and methods}

In 74 human skin wounds (surgical wounds, lacerations and stab wounds after surgical treatment) with a wound age between 1 day and 7 months, collagen types I and VI were localized by immunohistochemistry. In addition, postmortem wounds and uninjured skin were analyzed. The specimens were obtained and prepared as previously described $[3,4,5]$.

After enzyme pretreatment (trypsin, pronase) paraffin sections were stained using polyclonal antibodies against collagen I (Sanofi Diagnostics, Pasteur GmbH, Freiburg, Germany) according to the APAAP-method [6] and using polyclonal antibodies against collagen VI (kindly supplied by Dr. R. Timpl, Max-Planck-Institut für Biochemie, Martinsried, Germany) according to the ABC-method [10].

\section{Results}

\section{Uninjured skin}

In undamaged skin a positive reaction for collagen type I was observed diffusely throughout the dermis with a slightly pronounced staining in the stratum papillare. Furthermore, the adventitia of skin appendages as well as of blood vessels showed a distinct positive staining. The basement membrane of the epithelium, of blood vessels or skin appendages as well as those of muscle and nerve bundles remained negative for collagen type I.

Collagen type VI was also localized diffusely throughout the dermis with a more pronounced staining in the stratum papillare. In contrast to collagen type I, a positive reaction was observed adjacent to the basement membrane of the epithelium, of skin appendages, nerve and muscle fibers as well as of blood vessels.

\section{Postmortem skin wounds}

In skin wounds inflicted after death no reactivity was seen for both collagen I and VI apart from the normally reacting structures. In some specimens, however, positively staining string-like and sometimes ramifying structures due to destroyed connective tissue fibers or fat cells could be observed. These, however, showed no association with fibroblastic cells of the wound area.

\section{Skin wounds}

Collagen type I. A positive reaction in the form of small spot-like pericellular fragments associated with wound fibroblasts was first detectable in a skin wound with a post-infliction interval of approximately 4 days. Ramifying strings positively staining for collagen type I occurred first 5-6 days after wounding and were almost constantly observed in skin wounds aged between 7 days and approximately 1 month. Out of 18 lesions with a post-infliction interval between 4 and 6 days, $9(50 \%)$ showed negative results and in a further 2 cases $(11 \%)$ a questionable reaction was seen. In contrast, in only 2 out of 37 wounds
Table 1. Time dependent appearance of collagen types I and VI in human skin wounds

\begin{tabular}{llll}
$\begin{array}{l}\text { Collagen } \\
\text { type }\end{array}$ & $\begin{array}{l}\text { Earliest } \\
\text { appearance }\end{array}$ & $\begin{array}{l}\text { Regular } \\
\text { appearance }\end{array}$ & $\begin{array}{l}\text { Longest } \\
\text { appearance }\end{array}$ \\
\hline I & $\begin{array}{l}\text { 4-6 days } \\
\text { VI }\end{array}$ & $\begin{array}{l}6-7 \text { days } \\
6-7 \text { days }\end{array}$ & $\begin{array}{l}\text { months } \\
\text { months }\end{array}$ \\
\hline
\end{tabular}

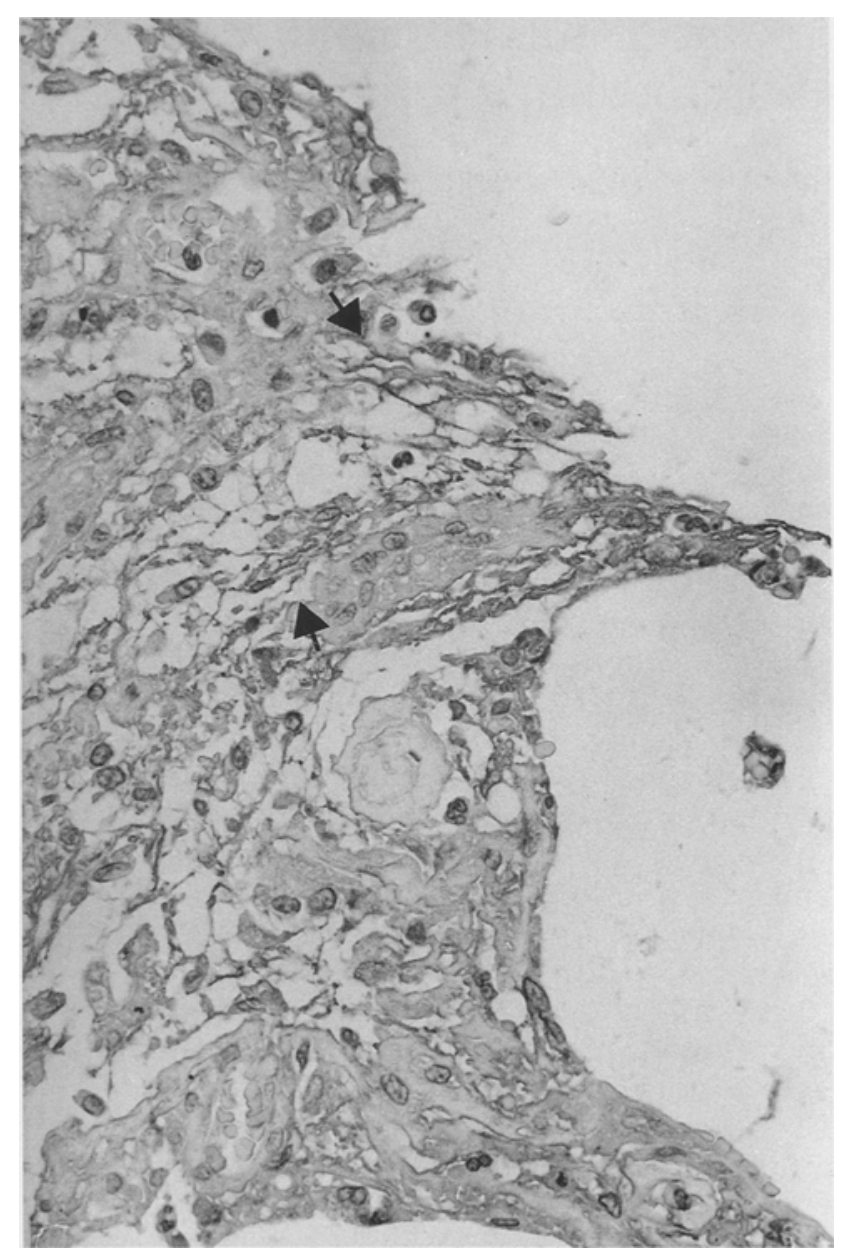

Fig.1. 8-day-old human skin wound: network-like structures (see arrows) at the wound edge positively staining for collagen I and associated with fibroblastic cells (paraffin, APAAP, $480 \times$ )

(5\%) aged between 7 days and 1 month was no positive staining detected in the wound area and in 1 lesion $(3 \%)$ the reaction was questionable.

In the granulation/scar tissue of lesions with advanced wound age (up to 3 months) a weak reactivity in the form of thin strands as well as positively reacting spotlike structures were seen associated with fibroblastic cells. The oldest skin wound investigated (post-infliction interval: 7 months), however, showed no staining pattern with significant differences to normal skin.

Collagen type VI. Positively reacting spot- and string-like structures around wound fibroblasts were first detectable after a post-infliction interval of approximately 3 days. Network-like structures showing an intense staining occurred in all cases $(n=31)$ aged between 6 and 31 


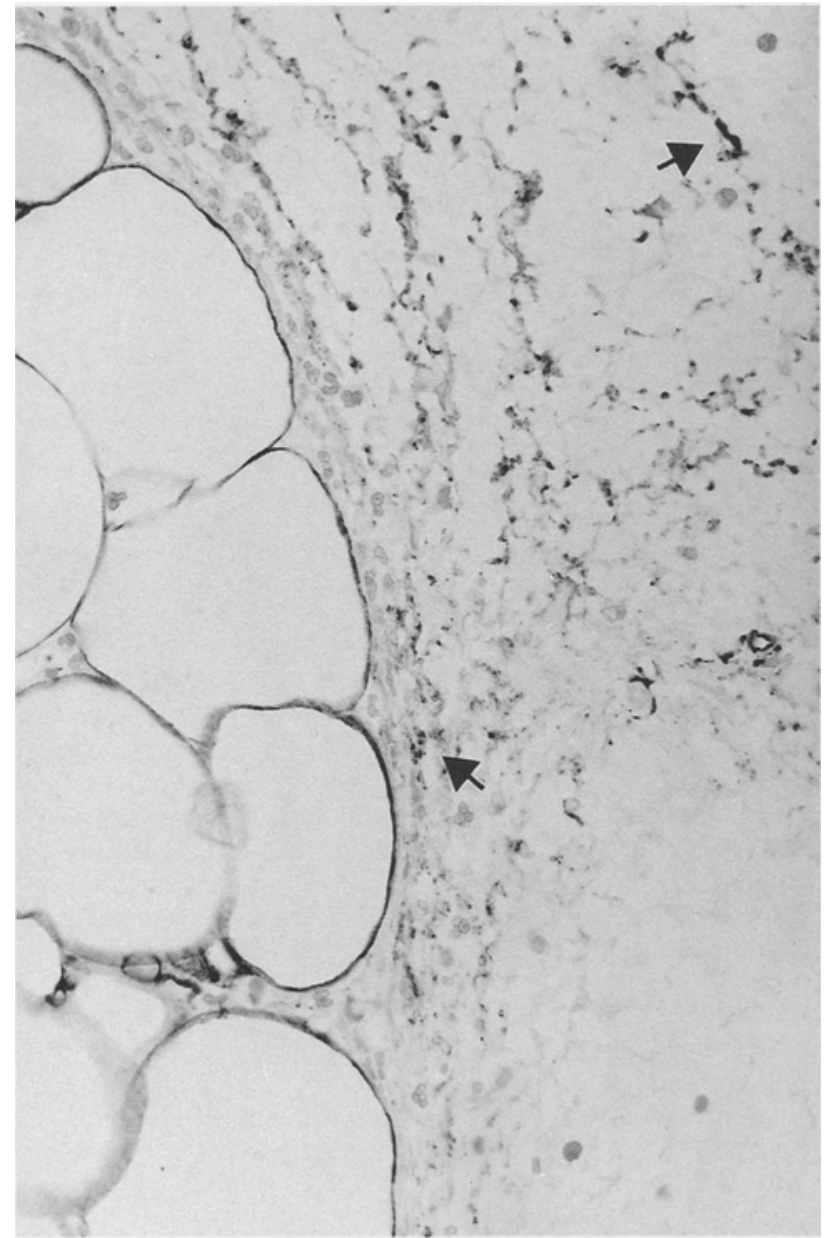

Fig. 2. 4-day-old human skin wound: spot- and string-like structures (see arrows) positively reacting with collagen VI in the subcutaneous layer (paraffin, $\mathrm{ABC}, 480 \times$ )

days. Only 3 out of 19 cases (26\%) aged between 3 and 5 days gave negative results.

In some lesions with advanced wound age (1-7 months) no positive reactions above the normal level for connective tissue staining were found in the granulation/scar tissue.

No relevant differences in the appearance of the investigated collagen types dependent on individual age or wound localization occurred exceeding the interindividual variability found in our series.

\section{Discussion}

In normal skin, collagen types I and VI are localized diffusely throughout the dermis and collagen VI also shows a pronounced reactivity close to basement membranes [18]. Both collagen types are basically important to maintain regular structural functions $[2,8,12]$. Furthermore, it has been discussed that collagen type VI is involved in cell-cell interaction [1].

In experimental studies it has been shown that different collagen types appear at different times during wound healing indicating that the specific detection of different collagen types can be used for a forensically applicable wound age estimation. Our own previous studies provided considerable evidence that the immunohistochemical detection of collagens III, IV and V show distinct time courses of appearance of the collagen types $[3,4$, 5]. Less information is available for collagen $I$.

Vialle-Presles et al. [19] detected collagen type I in bovine collagen-implants in rat skin after 7 days in association with collagen V. Collagen type III, however, appeared first 30 days after wound infliction. Kurita and co-workers [13] showed - in contrast to Vialle-Presles et al. [19] - an increased synthesis of collagen $V$ in the early phases of wound healing after tooth extraction in rabbits when compared to collagen type I. After 5 days they observed a decrease in the collagen V/I-ratio indicating an increased collagen I production at this point of time in comparison to collagen V. Kurkinen et al. [14] found a sequential appearance of fibronectin, procollagen III, collagen III and collagen I between 2 and 7 days after implantation of cell-stics in mouse skin. Other authors also described a delayed appearance of collagen type I when compared to other interstital collagen subtypes $[9,17]$. Studies dealing with the time-dependent appearance of collagen type I useful for a forensically applicable time estimation of human skin wounds have only been carried out by Eisenmenger et al. [7]. They reported that collagen $I$ is first detectable in wounds with a postinfliction interval of at least 6 days and therefore considerably later than collagen type III, which was observed first in wounds aged more than 2 days.

No time-dependent analysis of collagen VI in human skin wounds has yet been performed and only some experimental studies dealing with wound healing of the monkey and rabbit cornea exist $[15,16]$. These results, however, provide no information which is useful for a forensically practicable age determination of skin wounds. This also holds true for the study of Kawahara et al. [11] which deals with the appearance of different collagen types after ventriculotomy of the human heart.

In our series, collagen I appeared first after a wound age of 5-6 days in the form of ramifying string-like structures and a positive reaction in the form of spot-like fragments around fibroblasts occurred in a 4-day-old lesion. These results are comparable to the findings of Eisenmenger and co-workers [7] who first detected collagen I after a post-infliction interval of 6 days. Since they investigated a smaller number of specimens, the somewhat earlier appearance of collagen I in our material can be explained by the different number of samplings and an extended interindividual variability. According to the results of Eisenmenger et al. [7] it has additionally been shown that collagen III appears $2-3$ days after wound infliction and collagen $\mathrm{V}$ after approximately 3 days [5]. Therefore, our results support the findings of other authors $[7,9,13,14,17]$ who in general reported a delayed appearance of collagen I during wound healing when compared to other interstitial collagen subtypes.

In addition to the localization of collagen I, we analyzed the distribution of collagen VI in the wound area. This protein was detectable first approximately 3 days after wounding and the synthesis of collagen VI seemed to increase during wound healing in parallel to collagen 
$V$. In serial sections stained with antibodies for collagens III, V and VI, however, collagen VI appeared in slightly smaller quantities when compared to collagen $\mathrm{V}$ and particularly when related to collagen III. This is a further strong evidence for a sequential appearance of these collagen types during wound healing. Thus, it is conceivable that the localization of collagens III, V and VI as well as of collagen I can be used for an estimation of the wound age. For example, if there is a positive reaction for collagen III but not for collagen V, VI or I in serial sections of the lesion it can be concluded that this wound is aged at least 2-3 days, but less than 6-7 days.

The almost regular appearance of collagens I and VI 6-7 days after wound-infliction indicates that negative results in a sufficient number of specimens point to a wound age of less than 6-7 days, but usually an advanced wound age cannot be completely excluded. Positive results provide much more reliable information.

In comparison to collagens III and V [5], types I and VI were also detectable in the granulation/scar tissue of some older wounds (wound age up to 2-3 months) in enhanced amounts when compared to normal skin but in smaller quantities when related to skin lesions with shorter survival times. Therefore, the immunohistochemical analysis of different interstitial collagen subtypes cannot be used for an age estimation of lesions with advanced post-infliction intervals.

In summary, the immunohistochemical localization of collagens I and VI provides the following information useful for a forensically applicable age estimation of human skin wounds:

1. Network-like structures positively reacting for collagens I or VI indicate a wound age of at least 5-6 days and 3 days, respectively. Since positive reactions for collagen $I$ in the form of spot-like fragments around wound fibroblasts also occur in 4-day-old lesions an earlier appearance seems possible.

2. Since collagens I and VI appear almost constantly after post-infliction intervals of approximately 6-7 days, negative results in a sufficient number of specimens of the same skin wound indicate a wound age of less than 6-7 days. Negative results, however, should always be interpreted with caution and therefore, the lack of a positive reaction cannot completely exclude longer wound ages.

3. Collagens I and VI are also detectable in the granulation/scar tissue of some but not all wounds with advanced wound age in an enhanced intensity when compared to normal skin. Therefore, the immunohistochemical analysis of these collagen types cannot be used for a wound age estimation of older skin wounds.

4. The immunohistochemial analysis of different collagen types (types I, III, V and VI) can provide valuable information useful for a differentiation of the wound age. The different amounts of the collagens in the wound area are due to time differences in the initiation of the collagen synthesis.

This study was supported by grants from the "Deutsche Forschungsgemeinschaft" (grant Ei 209/3-1) and from the "Friedrich-Baur-Stiftung", University of Munich

\section{References}

1. Aumailley M, Mann K, Mark K von der, Timpl R (1989) Cell attachment properties of collagen type VI and Arg-Gly-Asp dependent binding to its alpha2(VI) and alpha3(VI) chains. Exp Cell Res 181:463-474

2. Becker J, Schuppan D, Hahn EG, Albert G, Reichart P (1986) The immunohistochemical distribution of collagens type IV, $\mathrm{V}, \mathrm{VI}$ and of laminin in the human oral mucosa. Arch Oral Biol 31:179-186

3. Betz P, Nerlich A, Wilske J, Tuibel J, Wiest I, Penning R, Eisenmenger $W$ (1992) The time-dependent rearrangement of the epithelial basement membrane in human skin wounds-immunohistochemical localization of collagen type IV and VII. Int J Leg Med 105:93-97

4. Betz P, Nerlich A, Wilske J, Tübel J, Wiest I, Penning R, Eisenmenger W (1992) The temporary pericellular expression of collagen type IV, laminin and heparan sulfate proteoglycan in myofibroblasts of human skin wounds. Int J Leg Med 105: $169-172$

5. Betz P, Nerlich A, Tübel J, Penning R, Eisenmenger W (1993) The meaning of immunohistochemical localization of collagens type III and V for the time-estimation of human skin wounds. Int J Leg Med

6. Cordell JL, Falini B, Erber WN, Ghosh AK, Abdulaziz Z, MacDonald S, Pulford AF, Stein H, Mason DY (1984) Immunoenzymatic labeling of monoclonal antibodies using immune complexes of alkaline phosphatase and monoclonal antialkaline phosphatase (APAAP-complex). J Histochem Cytochem 32:219-229

7. Eisenmenger W, Nerlich A, Glück G (1988) Die Bedeutung des Kollagens bei der Wundaltersbestimmung. Z Rechtsmed 100:79-100

8. Furthmayr H, Mark K von der (1987) The use of antibodies to connective tissue proteins in studies on their localization in tissues. In: Furthmayr H (ed) Immunochemistry of the extracellular matrix. Vol II, CRC Press, New York, pp 89-117

9. Gay S, Viljanto J, Raekallio J, Penttinen R (1978) Collagen types in early phases of wound healing in children. Acta Chir Scand 144:205-211

10. Hsu SM, Raine L, Fanger H (1981) A comparative study of the peroxidase-antiperoxidase method and an avidin-biotin-complex method for studying polypeptide hormones with radio immunoassay antibodies. Am J Clin Pathol 75:734-739

11. Kawahara E, Mukai A, Oda Y, Nakanishi I, Iwa T (1990) Left ventricúlotomy of the heart: tissue repair and localization of collagen types I, II, III, IV, V, VI and fibronectin. Virchows Arch [A] 417:229-236

12. Keene DR, Engvall E, Glanville RW (1988) Ultrastructure of type VI collagen in human skin and cartilage suggests an anchoring function for this filament network. J Cell Biol 107:1995-2006

13. Kurita K, Hashimoto Y, Takei T, T, Kawai T, Hayakawa T (1985) Changes in collagen types during the healing of rabbit tooth extraction wounds. J Dent Res 64:28-32

14. Kurkinen M, Vaheri A, Roberts PJ, Stenman S (1980) Sequential appearance of fibronectin and collagen in experimental granulation tissue. Lab Invest 43:47-51

15. Malley DS, Steinert RF, Puliafito CA, Dobi ET (1990) Immunofluorescence study of corneal wound healing after excimer laser anterior keratectomy in the monkey eye. Arch Ophthalmol 108: 1316-1322

16. Murata $Y$, Yoshiaka H, Kitaoka M, Iyama K, Okamura R, Usuku G (1990) Type VI collagen in healing rabbit corneal wounds. Ophthalmic Res 22:144-151

17. Remberger U, Hübner G (1979) Experimentelle Untersuchungen über Zell- und Gewebsreaktion nach Implantation von xenogenem Kollagenschaum. Res Exp Med (Berl) 175:67-69

18. van der Rest M, Garrone R (1991) Collagen family of proteins. FASEB J 5:2814-2823

19. Vialle-Presles MJ, Hartmann DJ, Frane S, Herbage D (1989) Immunohistochemical study of the biological fate of subcutaneous bovine collagen implant in rat. Histochemistry 91 : 177-184 